Max-Planck-Institut für demografische Forschung Max Planck Institute for Demographic Research Konrad-Zuse-Strasse 1 - D-18057 Rostock · GERMANY

Tel +49 (0) 3812081 - 0; Fax +49 (0) 3812081 - 202;

http://www.demogr.mpg.de

MPIDR WORKING PAPER WP 2004-022

AUGUST 2004

\title{
Fertility of internal migrants: comparison between Austria and Poland
}

Hill Kulu (kulu@ demogr.mpg.de)

This working paper has been approved for release by: Andres Vikat (vikat@demogr.mpg.de)

Deputy Head of the Laboratory of Contemporary European Fertility and Family Dynamics.

() Copyright is held by the authors.

Working papers of the Max Planck Institute for Demographic Research receive only limited review. Views or opinions expressed in working papers are attributable to the authors and do not necessarily reflect those of the Institute. 


\begin{abstract}
Previous research has proposed four competing views on an individual's fertility following a move from one social context to another. Each view has received support but has also been challenged by literature. This study contributes to the existing discussion on fertility by providing an analysis of the effects of internal migration on the fertility of post-war Austrian and Polish female cohorts. We base our study on retrospective event-history data and apply intensity regression to both single and simultaneous equations. Our analysis shows, first, that natives in urban areas in general and in the large cities in particular have lower fertility compared to non-migrants in rural areas, both in Austria and Poland. Second, it reveals that people who move from one place to another adopt the fertility behaviour that is dominant at destination. Third, we observe an elevated first birth risk for women who move because of union formation, and a short-term postponement of childbearing for those who settle in a large city. Our country comparison shows some differences in fertility variation across settlements, but, overall, the results are quite similar, despite the different post-war societal context of two countries.
\end{abstract}

Keywords: fertility, internal migration, intensity regression, simultaneous equations, Austria, Poland 
Two major research streams exist concerning the childbearing of people who move from one social context to another. The first focuses on the fertility of immigrants in (economically) developed countries in general and North America in particular (Stephen and Bean 1992; Kahn 1994); the second investigates the fertility of rural-urban migrants within a Third World context (Goldstein and Goldstein 1981; Lee and Pol 1993; Brockeroff and Yang 1994). The changing demography of the societies of interest to fertility research, no doubt, has induced and fed these research streams. More specifically, increasing numbers of immigrants from high fertility regions of the world have driven research on immigrants' fertility in developed countries, while growing numbers of migrants from high-fertility rural areas to low-fertility urban centres has motivated studies on migrants' fertility in (economically) less developed countries. Childbearing behaviour of migrants has thus not only emerged as an interesting research topic, but also has become critical to the understanding of current and future fertility trends in many societies.

At first glance, the lack of lively research on the childbearing behaviour of internal migrants in developed countries is not surprising. Nowadays the majority of people in low-fertility societies live in urban areas, and the fertility differences (if any) between various types of locations are obviously not very large. Therefore, we do not expect a large change in the fertility levels of people who move from one place to another, neither should patterns of population redistribution play any (more a) significant role in shaping national fertility trends. Interestingly, however, the few studies on this topic that exist show that people in rural settlements and small towns still exhibit significantly higher fertility levels compared to the population in large cities (Courgeau 1989; Mulder and Wagner 2001). While long-term population concentrations in developed countries obviously have had a lowering impact on overall fertility levels, more recent trends of sub- and counter-urbanisation (Champion 2001) may conversely have an opposite effect, depending on how and whether changing social context shape migrants' fertility. 
In this paper, we study childbearing behaviour of internal migrants in two European countries: Austria and Poland. Our objectives are, first, to look at fertility differences between people who move and those who stay in various types of settlements; second, to study the factors proposed in the literature behind the fertility patterns of migrants. We use retrospective event-history data and apply intensity regression to both single and simultaneous equations, with the aim of gaining a deeper insight into the causes of migrants' fertility behaviour. The structure of the article is as follows. First, we outline different views on the impact of migration on fertility. Then, we describe the study contexts and form hypotheses for our research. Third, we introduce the data, methods and modelling strategy. Fourth, we present the results of our analyses, followed by a discussion on the role of migration in shaping people's childbearing behaviour.

\section{Fertility of migrants: four different views}

Previous research has proposed four different hypotheses on an individual's fertility following a move from one social context to another (Hervitz 1985; Rundquist and Brown 1989; Lee 1992; Singley and Landale 1998; Kulu 2003a; Lindstrom 2003; Andersson 2004). Each view draws from some theoretical understanding, assuming some factors to be more important than others in shaping an individual's childbearing preferences and behaviour.

The socialisation hypothesis emphasises the critical role of the social environment during childhood. Values and norms dominant during childhood shape an individual's 'habitus' or 'mode of orientation' (Bourdieu 1990) which, in turn, to a large extent guides her/his behaviour in later life. Therefore, people who move from one social environment to another exhibit fertility levels similar to those who stay at origin (residence during childhood), and convergence towards fertility levels at destination occurs in the next generation only (given that differences between locations do exist). Besides stressing the importance of the socio-cultural environment during childhood, the 
socialisation hypothesis assumes internal homogeneity across values and norms for similar types of places, and that an individual's fertility preferences (and behaviour) are relatively stable (if not fixed) over the life course. The socialisation hypothesis (also called assimilation hypothesis) has been popular in literature on immigrants (Rosenwaite 1973; Stephen and Bean 1992; Kahn 1994), but has also found support in early research on fertility of internal migrants in developed countries (Goldberg 1959; Freedman and Slesinger 1961; Duncan 1965).

The adaptation hypothesis assumes that an individual's immediate or current social context rather than the childhood environment matters most in her/his childbearing behaviour. Moreover, it emphasises the importance of both socio-cultural and economic factors. Dominant values and norms concerning the family, childbearing and gender roles shape an individual's fertility preferences and behaviour, no matter where an individual originally comes from. Similarly, economic opportunities and constraints that are present during current residence promote or hinder an individual's childbearing behaviour. Therefore, people who move from one socio-cultural and economic environment to another adapt to the fertility behaviour prevalent at the destination environment. While adaptation to economic conditions should occur soon after migration, the adoption of norms and values at destination may take longer and occur gradually. The adaptation hypothesis has been tested and supported by many studies on fertility of rural-urban migrants in Third World countries (Farber and Lee 1984; Brockeroff and Yang 1994). Some studies that support this hypothesis when applied to developed countries can also be found (Courgeau 1989; Kulu 2003a).

The selection hypothesis assumes that people who move from one social environment to another display fertility levels similar to the population at destination. However, this cannot be attributed to a change in their fertility, but to the fact that migrants are a selective (or non-random) group of people whose fertility preferences are different from those of the population at origin, and similar to the people at destination. The selectivity may occur on the basis of 
observed characteristics, such as education or occupation, or unobserved characteristics, such as social mobility ambitions (Macisco et al. 1970; Hoem 1975) or family-proneness (Kreyenfeld 2002, 37). Thus, the selection hypothesis (in its latter form, at least) emphasises the importance of childhood in shaping an individual's fertility preferences - as the socialisation hypothesis does - but assumes that these preferences are group or individual rather than simply place-specific. The selection hypothesis has been discussed in many papers (Myers and Morris 1966; Goldstein and Goldstein 1981; Murphy and Sullivan 1985), but only few studies have addressed the issue explicitly (Courgeau 1989, Michielin 2002; Kulu 2003a). Recently, studies on immigrants' fertility have extended the issue by showing how residential moves motivated by union formation and/or childbearing intentions produce elevated fertility immediately after migration (Singley and Landale 1998; Andersson 2004). Again, migration is an effect rather than the cause of fertility intentions.

The disruption hypothesis, finally, argues that the impact of the migration event itself on fertility patterns of migrants should be taken into account. Migration brings with it economic costs and socio-psychological stress associated with the process of residential relocation or the change in environment. In addition, couples may intentionally delay childbearing until the move has been completed and some general and economic adjustments to the new location are made. Therefore, migrants show particularly low levels of fertility immediately following migration because of the disruptive factors associated with the move. The drop in fertility, however, should be only temporarily, and the pace of fertility should resume gradually to its usual pattern. The disruption hypothesis has found support in many studies that focus on the fertility of both internal and international migrants (Goldstein 1973; Carlson 1985; Brockeroff 1995; White et al. 1995).

We have previously described four hypotheses in their 'ideal-type' form, showing that they are distinct from each other. The reality, however, may not be so simple as each of them assumes, and originally contradictory views may 
be supported simultaneously and thus turn out to be complementary. Still, we briefly summarise major differences between the hypotheses above, with the aim of gaining a deeper insight into the underlying ideas and implications. First and most importantly, the socialisation and selection hypotheses emphasise that childhood plays a critical role in the formation of an individual's childbearing preferences, and that these preferences do not change much later in life, whatever the context. Fertility preferences reflect those displayed by the sociogeographical context of childhood, the parental home or some other factors that are important in early personality development. The adaptation and (with some reservations) also the disruption hypothesis, in contrast, assumes that fertility preferences and behaviour are subject to change during an individual's life course, this in response to a changing social context. Second, it seems that the socialisation and selection hypotheses attribute in the main cultural factors to an individual's fertility behaviour, while the adaptation and disruption hypotheses consider economic resources as being of importance also. (Naturally, economic conditions during an individual's childhood may also shape her fertility later in life (Easterlin 1980); however, this kind of argument has not yet been put forward and tested in the literature on migrant fertility.)

As competing views exist on migrants' fertility, there is room and need for further research aimed at advancing our understanding of how and whether migration shapes an individual's childbearing behaviour. Moreover, some shortcomings of previous studies further motivate our current undertaking. First, most research uses cross-sectional census data, while retrospective eventhistory or longitudinal data have found only limited use, despite their dominant position in many areas of demographic research. Yet, the lack of information on the precise timing of migration and childbearing events restricts any causal inferences about the migration-fertility relationship. Second, recent studies have successfully controlled migrants' selectivity across standard personal characteristics, while the role of unobserved selectivity has been discussed by many, but explicitly addressed only in few papers (Courgeau 1989, Michielin 2002; Kulu 2003a). Third, most studies look at migration from one social 
context to another (from one country to another, from rural to urban settlements), while counter-streams have not been investigated. This strategy may be justified when studying fertility of international migrants or internal migrants in Third World countries, but not when looking at the fertility of migrants in developed countries. Moreover, a simple urban-rural-distinction (often used) may not be enough to capture fertility variation across origin and destination of migration. Finally, most work focuses on country case studies. Comparative research with similar data and methodology in various countries no doubt allows us to gain a deeper insight into the patterns and causes of migrants' fertility. Before we present the hypotheses for our study, we will briefly describe the context of our research.

\section{Long-term fertility and migration trends in Austria and Poland}

Transition to the 'modern fertility regime' in Austria can be traced back to the late 19th century, when previously fluctuating birth rates began to decrease (Chesnais 1992, 236). The decline was particularly rapid in the first two decades of the 20th century, and replacement level fertility was achieved in the country as early as in the 1920s (Chesnais 1992, 207). The decline of fertility in Poland, in turn, began later and from higher levels, and it was slower. As a result, fertility was still very high (with a TFR of about 3.5) before WW II (Chesnais 1992, 238; Holzer and Kowalska 1997, 11-12). Post-war developments were also different in the two countries. Austria, as many Western countries, experienced the post-war 'baby-boom' (Coleman 1996, 13). Period fertility increased in the second half of the 1950s, and in the early 1960s the TFR peaked at the level of 2.8 children per woman (SA 2004a). Thereafter, fertility gradually declined and the TFR stabilised at the level of 1.4 in the late 1980s. While some decreases in period fertility resulted from continuous postponement of childbearing (Coleman 1996, 21), decreasing rates of third and higher-order births accounts for most of the declines (Buber and Prskawetz 2000, 6; Hoem et al. 2001b, 251). Fertility in Poland, still at very high levels in 
the immediate years following the war (with a TFR of about 3.7), decreased until the late 1960s (Holzer and Kowalska 1997, 11). Thereafter it remained above replacement level until the late 1980s when a rapid fertility decline common to all post-socialist countries began (Macura and MacDonald 2003).

Post-war developments in population migration were no less dynamic in any of the two countries. In Austria, population movements towards the major urban centres and sub-urbanisation in urban regions were dominant trends. While sub-urbanisation was modest until the 1970s, it increased thenafter, and gradually extended beyond the borders of urban regions, especially that of Vienna (SA 2004b). Moreover, the net migration of larger cities turned negative in the 1990s due to increasing out-migration from the major cities, allowing us to hypothesise on the phenomenon of counter-urbanisation (cf. Champion 1993, 31). Surprisingly, however, the share of the urban population did not increase despite extensive rural to urban migration, but remained stable over the whole post-war period. Sixty four percent of the 1950 Austrian population lived in urban areas, while the corresponding figures for 1970, 1990 and 2000 were 68\%, 67\% and 67\% (UN 2002, 166-167). Positive natural increases in rural and negative ones in urban areas kept the balance in the early post-war period, while at a later stage increasing numbers of immigrants in the cities most likely compensated population losses there (SA 2004a, 49-50).

Urbanisation was also a dominant trend in post-war Poland (Kupiszewski et al. 1998; Kok 1999; Rykiel and Jażdżewska 2002). Extensive rural to urban migration was driven by massive industrialisation, the latter which was a major economic priority of the Polish central authorities, similarly to that in other planned economies. As opposed to Austria and other market economies, sub-urbanisation was modest in Poland. Areas close to large cities grew, but mostly due to in-migration from rural areas and small towns. This phenomenon, known as 'rural urbanisation', largely resulted from housing shortage in the cities and administrative restrictions on in-migration to the cities aimed at regulating urban growth (Rykiel and Jażdżewska 2002, 278). (On the contradiction between economic and spatial policies in planned 
economies, see Buckley 1995.) Since the late 1980s, however, rural-urbanmigration decreased considerably, and suburban areas began to receive migrants from the cities in increasing numbers (Kupiszewski et al. 1998, 280; Rykiel and Jażdżewska 2002, 284). Due to long-term population concentrations of the Polish population, the share of the urban population grew significantly until very recently. There were $39 \%$ of the Polish population living in urban areas in 1950; the corresponding figures for 1970, 1990 and 2000 are 52\%, $61 \%$ and $62 \%$ (UN 2002, 166-167).

Fertility and migration trends in the two countries have been studied in detail, but little is known neither about the childbearing patterns of rural to urban and other migrants nor the fertility differences across the settlement hierarchy. The rural-urban fertility gap in Poland (Holzer and Kowalska 1997, 11; Vojtěchovská 2000, 256) and the traditionally lower fertility in Vienna compared to the rest of Austria (Sauberer 1981, 19; Chesnais 1992, 124; Lutz et al. 2003, 185) are the only established facts we can find from previous research. In this context, a comparative analysis of fertility trends for urban and rural areas in the two countries becomes informative. While the comparison does not reveal much on fertility of internal migrants, it still serves as a factor motivating our current research and as a source for our hypotheses. It appears that fertility in urban areas has systematically been lower than that in the rural areas of both countries. The gap has decreased over time, but still exists. In the 1960s and the 1970s, urban areas exhibited a fertility that was 25-30\% lower in Austria and about 40\% lower in Poland, and in the 1980s and the 1990s, the corresponding figures were 10-20\% for Austria and about 30\% for Poland (Figure 1$)^{1}$. It is also of interest that below replacement fertility in urban areas has a longer history than we expected, and that relatively high fertility in rural areas was responsible for replacement level fertility until the 1970s and the 1990s in Austria and Poland, respectively. Moreover, although comparative data are not available, we may assume that fertility in large cities in both countries has obviously been at low levels for a very long time (cf. Lutz et al. 2003, 185). 


\section{Hypotheses on fertility of internal migrants}

Our hypotheses come from previous two sections, and are as follows. First, we assume that childbearing patterns vary across settlement hierarchy in both Austria and Poland. More specifically, fertility levels decrease as the size of settlement increases. We also believe that the differences remain even after controlling for possible compositional differences across (observed) population characteristics. Second, we draw from recent internal fertility literature on migration and hypothesise that, overall, migrants exhibit fertility levels similar to those of the population at destination (Brockeroff 1995; Lindstrom 2003; Kulu 2003a). We assume that this hypothesis also holds when controlling for the impact of (observed) personal characteristics. If so, then an answer to the issue of adaptation versus (unobserved) selection becomes a major task in our further analysis. Do we observe behavioural change in migrants because of the changing socio-cultural and economic context, or do we have people of high social mobility ambition or family-proneness, depending on the destination of migration?

Third, we certainly expect to find some selection effects as residential relocation is often related to union formation, and thus may be followed by elevated fertility levels for first conception (Singley and Landale 1998; Andersson 2004). This selectivity by reason of migration can be controlled for when including partnership status and union duration in the analysis. Thus, we may initially observe a higher (first) birth risk for migrants than for the destination population, but this difference should disappear after controlling for partnership status. Fourth, we have reasons to assume a drop in fertility levels immediately after the move for people who move for reasons other than union formation. The decline caused by disruptive factors associated with residential relocation may be steeper for migrants moving to large cities, but presumably may be a temporary phenomenon (cf. White et al. 1995; Kulu 2003a). Concerning our country comparison, we believe that the major results are not 
very different between the two countries, despite their slightly different fertility and migration histories, and post-war societal contexts. As fertility has been varying across settlement hierarchy in both countries, we may assume that the childbearing behaviour of migrants was also quite similar in the two countries. A context-specific characteristic, however, that might have produced some differences between countries is the fact that in planned economies a couple's chances to receive state housing increased considerably after having had a child (Katus et al. 2002, 156). If this played a role in family planning, we may expect elevated-fertility patterns for marriage-driven urban-bound migrations that are stronger in Poland than in Austria.

\section{Data, definitions and variables}

Our data come from the Austrian and Polish Family and Fertility Surveys. The Austrian FFS was carried out in 1995 and 1996 among 4,581 women and 1,539 men aged 20 to 54 (Prinz et al. 1998, 1, 53) (Table 1). The overall response rate was $72 \%$, which is rather good for a study of this content in present-day Austria (Hoem et al. 2001b, 252). The Polish FFS was carried out in 1991 among 4,209 women and 4,335 men aged 18 to 49, with a response rate as high as 95\% (Holzer and Kowalska 1997, 49-51). Being part of the European-wide FFS program, both surveys are based on a collection of event-histories. All major demographic events that took place in the respondent's life were identified (to the accuracy of the month), including births, co-residential unions and residential changes since age 15 .

Our research populations consist of 3,980 Austrian women born 19411976 and 4,109 Polish women born 1942-1973. We excluded from the Austrian sample foreign-born people and those who lived abroad at age 15. In addition, individuals who delivered incomplete data, gave first birth before age 15 or adopted a child were removed from both samples. We study the impact of internal migration on first, second and third conceptions (leading to births). There were 2970, 1853 and 630 such events in the Austrian and 3148, 2177 and 
857 in the Polish data, respectively. Our definition of migration to some extent varies across countries. For Austria, we define a residential change crossing the border of a district (Politischer Bezirk) as migration, whereas for Poland a residential change over the border of a commune (gmina) is counted as migration. The difference results from differences in data collection: while information on the destination of a residential change was collected at the level of district and region (but not at the commune level) in Austria, the Polish respondents were requested to provide information on the destination settlement of inter-commune moves. Although the Austrian data contains information on all settlement changes, we restrict our analysis to residential changes between districts. This is because, first, many settlement changes are short-distance local moves within the same commune. Second, Polish communes fall in-between Austrian communes and districts by average size of area and population.

We go beyond the traditional rural-urban-dichotomy and distinguish three types of settlements of origin and destination of migration: rural areas, small towns and large cities. Urban areas over 100,000 inhabitants are considered large cities, whereas urban settlements below 100,000 people are defined as small towns ${ }^{2}$. The distinction between rural areas and small towns was straightforward for Poland (because rural settlements form a separate category in the data) but more difficult for Austria as direct information on the type of settlement of origin and destination in Austria was not available. We defined as rural areas those Austrian districts in which the population of the largest settlement did not exceed 20,000 people. This turned out to be the best (among many others) when we compared our results with information on the type of settlement of residence at interview, information that the Austrian data contains $^{3}$. One more issue needs to be considered here - the borders of the cities. While for Poland this issue does not require attention because suburbanisation was insignificant until very recently, it is an issue in the case of Austria. Recent data provided by Statistics Austria show that all major cities extend beyond their administrative borders (Fuchs 1997). However, we defined 
the neighbouring districts as part of the city only for Vienna and not for other cities. We proceeded from the fact that the majority of events we looked at in our study took place from the 1960s to the 1980s, when sub-urbanisation was not as spread as in present-day Austria.

We split the two data sets by conception episode following the general logic of event-history data set up. Individuals are at risk since age 15 (for the first conception) or previous birth (for the second and third conception). The final censoring takes place at interview (in fact, nine months before) or at age 45. Residential episodes outside the country are excluded from the analysis for Austria. (We do not have any information on emigration and return migration of individuals for Poland, but the number of such episodes is certainly small as international migration in general and return migration in particular were negligible during the socialist period.) When conception occurred in the same month as migration and union formation, we used the sequence of events as follows: migration, union formation and conception. Thus, we assigned simultaneous conceptions to the destination environment. This strategy, as we will see later, allowed us to study in greater depth elevated fertility associated with residential changes driven by union formation. In addition, we built two multi-episode data sets for migration, which we needed for simultaneous analyses. The risk of migration starts at age 15 or at previous migration. In total, there are 2067 migration events in the Austrian and 3077 in the Polish data. Corresponding numbers by destination of migration are as follows: 947 and 888 to rural areas, 435 and 1164 to small towns and 685 and 1025 to large cities. We noticed variations across the two countries, which obviously results from slightly different definitions of migration and the type of settlement of residence.

Variables reflecting an individual's migration history hold a central position in our models. We include in the analysis a time-varying variable showing an individual's current residence and a variable indicating residence at age 15 (for migrants). Table (2) provides the distribution of birth events (conceptions) and the time that individuals were under risk across all 
combinations of categories of two variables for the two countries. The number of categories we use in the main analysis, however, will be smaller, but we will address this issue later. (In addition, an originally "static" variable showing current residence for migrants becomes "dynamic" when the risk of conception at destination is allowed to vary over time since migration, instead of being constant.) We control for several demographic variables when testing various hypotheses concerning the impact of residential change on childbearing. First, we include an individual's age and time since previous birth (for the second and third conceptions). Second, we control for partnership status and union duration. We also include a calendar time to capture the impact of the changing context.

Next, we include education enrolment, employment status and the level of education to control for the effect of an individual's socio-economic characteristics. We also use the number of siblings to individuals and her religiosity. Finally, we included the number of migrations to capture the "interim" experience of migrants and the reason behind migration to further control for the selectivity of migrants. Several other variables for both countries were available in preliminary analyses (e.g. showing parental divorce, whether the previous child was with the same partner or not, whether the previous child was born in the current residence or not). We also tested the effects of some variables that were available only for one of the two countries (the education of the respondent's father, the distribution of housework activities between parents). We exclude all these variables from our main analysis because their effect on fertility was not significant or their impact did not change the effect of residential change on fertility. The strategy based on the latter is known as a harmless misspecification of the model (Hoem 1995).

\section{Methods and modelling strategy}

We use intensity regression or (multivariate) indirect standardisation (Hoem 1993) as a research method. We estimate several models to examine in greater 
detail various hypotheses proposed by the literature. We begin with a simple model, looking at the effect of migration on conception and controlling for only age and time since previous birth (for the second and third births). We then include in our analysis partnership status and union duration with the aim of seeing the extent to which residential relocation driven by union formation influences migrant fertility. In the third model, we also control for the socioeconomic selectivity of migrants when assessing the effects of residential change on childbearing. Our basic model can be formalised as follows:

(1) $\ln \mu_{i}(t)=y(t)+\sum_{k} z_{k}\left(u_{i k}+t\right)+\sum_{j} \alpha_{j} x_{i j}+\sum_{/} \beta_{l} w_{i j}(t)$

where $\mu_{i}(t)$ denotes the intensity of (first, second or third) conception for individual $i, y(t)$ denotes a piecewise linear spline that captures the impact of baseline duration on the intensity. $z_{k}\left(u_{i k}+t\right)$ denotes the spline representation of the effect of a time-varying variable that is a continuous function of $t$ with origin $u_{i k} \cdot x_{i j}$ represents the values of a time-constant variable and $w_{i l}(t)$ represents a time-varying variable whose values can change only at discrete times.

We then look at the role unobserved selectivity possibly plays in accounting for differences between movers and stayers (which we expect to find). We build a simultaneous-equations model to estimate jointly three equations for fertility and another three equations for migration according to migration destination. We identify a person-specific heterogeneity term for the fertility equations and person-specific residuals for each migration equation as selectivity of migrants may vary according to their destination. Allowing correlation between the (person-specific) residual of fertility and those of migration equations, we identify possible migration endogeneity in the fertility process and control for unobserved selectivity when analysing the impact of residential change on childbearing (Lillard 1993). The model can be formalised as follows: 


$$
\begin{aligned}
\ln \mu_{i}^{C 1}(t) & =y^{C 1}(t)+\sum_{k} z_{k}^{C 1}\left(u_{i k}+t\right)+\sum_{j} \alpha_{j}^{C 1} x_{i j}+\sum_{l} \beta_{l}^{C 1} w_{i j}(t)+\varepsilon_{i}^{C} \\
\ln \mu_{i}^{C 2}(t) & =y^{C 2}(t)+\sum_{k} z_{k}^{C 2}\left(u_{i k}+t\right)+\sum_{j} \alpha_{j}^{C 2} x_{j i j}+\sum_{l} \beta_{l}^{C 2} w_{i /}(t)+\varepsilon_{i}^{C} \\
\ln \mu_{i}^{C 3}(t) & =y^{C 3}(t)+\sum_{k} z_{k}^{C 3}\left(u_{i k}+t\right)+\sum_{j} \alpha_{j}^{C 3} x_{i j}+\sum_{l} \beta_{l}^{C 3} w_{i /}(t)+\varepsilon_{i}^{C} \\
\ln \mu_{i m}^{R}(t) & =y^{R}(t)+\sum_{k} z_{k}^{R}\left(u_{i m k}+t\right)+\sum_{j} \alpha_{j}^{R} x_{i m j}+\sum_{l} \beta_{l}^{R} w_{i m /}(t)+\varepsilon_{i}^{R}, \\
\ln \mu_{i m}^{S}(t) & =y^{S}(t)+\sum_{k} z_{k}^{S}\left(u_{i m k}+t\right)+\sum_{j} \alpha_{j}^{S} x_{i m j}+\sum_{l} \beta_{l}^{S} w_{i m /}(t)+\varepsilon_{i}^{S} \\
\ln \mu_{i m}^{L}(t) & =y^{L}(t)+\sum_{k} z_{k}^{L}\left(u_{i m k}+t\right)+\sum_{j} \alpha_{j}^{L} x_{i m j}+\sum_{l} \beta_{l}^{L} w_{i m /}(t)+\varepsilon_{i}^{L}
\end{aligned}
$$

where $\mu_{i}^{C l}(t), \mu_{i}^{C 2}(t), \mu_{i}^{C 3}(t)$ denotes the intensities of the first, second and third conceptions, respectively, and $\mu_{i m}{ }^{R}(t), \mu_{i m}{ }^{S}(t), \mu_{i m}{ }^{L}(t)$ represents the risks of migration to rural, small urban and large urban destinations in the competing risk framework ${ }^{4} . \varepsilon_{i}^{C}, \varepsilon_{i}^{R}, \varepsilon_{i}^{S}$ and $\varepsilon_{i}^{L}$ are person-specific heterogeneity terms for fertility, migration to rural, small urban and large urban areas, respectively. The identification of our model is attained through within-person replication: many women have given several births, and some people have made several moves to the same destination (cf. Lillard et al. 1995, 446).

Finally, we study the fertility patterns of migrants at destination in greater detail. We extend our previous models, allowing the intensity of conception to vary over time since arrival in the settlement instead of assuming a constant risk (we did so far). Technically, this is achieved by substituting the "jump-function"-representation with the linear-spline-representation of the effect of residential change on childbearing. We look at the patterns of first conception only as expected changes are most colourful here and the number of events sufficiently large for a more detailed analysis.

\section{Effect of migration on fertility in two countries}

We began our analysis by running a set of models to study the impact of various destination environments on childbearing of migrants with different origins (residence at age 15 or previous residence). For both countries, our analysis showed no significant variation among migrants with different origins living in the same destination environment. Thus, we collapsed the categories 
of origin and left only destination of migration in our main analysis, with two exceptions: residence at age 15 is included in the models for second birth (Poland) and for third birth (Austria). The major residential categories we then use are as follows: non-migrational and migrational episodes in rural, small urban and large urban areas. The episode is non-migrational if an individual has not moved since age 15. Migrational episodes are defined according to destination whatever the origin of migrants.

Let us now present the results of our main analysis. We begin our comparative analysis with the patterns of first birth across three basic models, and then move to second and third births. In the first model, we look at the effect of migration on first conception, controlling for age of women only. We see quite similar patterns for the two countries (Tables 3 and 4, Model 1). First, the larger the settlement, the lower the risk of first conception among nonmigrants. Second, and more interestingly, in all destinations (except the large cities of Austria) migrants exhibit fertility levels that are far above average, and the levels relative to those of non-migrants are particularly high in Poland. Migrants in rural areas in Austria and those in small towns have a risk of first birth that is higher by $33 \%$ and $21 \%$, respectively, compared to natives in rural areas, while the corresponding figures for Poland are 3.3 and 2.2 times as high, and $22 \%$ for migrants in the large cities. Next, we control for partnership status and union duration (Tables 3 and 4, Model 2). The fertility levels of migrants decrease significantly, and migrants now display fertility levels similar to those of non-migrants at destination. Clearly, the elevated migrant fertility pattern we originally observed for both countries did result from a significant portion of residential changes driven by family formation among all migrations.

In the third model, we also control for the socio-economic selectivity of the population, in addition to the number of migrations and the reason for their residential change. We see that the differences across the settlement hierarchy become smaller, but remain significant, and that migrants still exhibit fertility levels similar to those of natives at destination (Tables 3 and 4, Model 3). Some variation across countries can also be noticed. While the intensity of first 
conception decreases with increasing size of settlement in Austria, only residents of the large cities differ from others as they have lower fertility levels in Poland. Concerning the effect of two migration-related characteristics, we see, first, that people who have moved twice and more face a higher risk of first conception in Austria than those who have changed their residence once only. There is no such difference for Poland. Second, migrants who move for familyrelated reasons have a higher intensity of first conception in Austria (even after having controlled for partnership status and union duration), whereas higher fertility levels can be associated with housing-related moves in Poland.

The patterns of second conception are also interesting, although they change much less across the models. As the changes are negligible, we pass the first two models and report the results of the third model only. We see that the intensity of second conception is relatively low in the large cities of both countries, and that migrants exhibit fertility levels similar to non-migrants at destination (Tables 3 and 4, Model 3). The major difference between the countries stems from the fact that the rural-urban-distinction clearly is evident in Poland, while the residents of the large cities differ from others in Austria. This is opposite to the patterns we observed for first birth. Another difference is that the origin of migrants also matters for Poland. More specifically, migrants who come from large cities have a relatively low fertility in all destinations, a finding that is not very surprising. The impact of the number of migrations is not significant in either country (the reason for migration was not included in the analysis as it had relevance for a small group of people only who had moved after first birth).

The patterns of third conception are similar to the previous ones, although they have a specific character as well. Again, we report the results of the third model only, as the changes across the models are not significant. We see, first, that the residents of the large cities have a relatively low intensity of third conception in Austria, while in Poland the risk is also low for people in small towns (Tables 3 and 4, Model 3). This is similar to what we observed for second births. Second, overall, migrants display fertility levels similar to those 
of non-migrants at destination, but the patterns are less uniform than for first and second births. Surprisingly, migrants in rural areas in Austria have a significantly lower risk of third conception compared to natives. A relatively low risk for migrants of rural origin is also striking. Nevertheless, our major findings across the three births for both countries show that people in urban areas in general and in the large cities in particular have a lower fertility compared to those living in rural areas. Further, migrants exhibit fertility levels similar to those of non-migrants at destination, with some minor exceptions. Clearly, our next step is thus to study whether migrants change their behaviour in response to a change in the social context or whether we are dealing with people whose fertility preferences are similar to those of the population at destination.

To identify and control for unobserved selectivity of migrants, we next include in the analysis a person-specific residual for fertility equations and separate residuals for each migration equation, allowing for a correlation between the heterogeneity terms. The model fit improves significantly for both countries. The standard deviations of all heterogeneity terms are significantly different from zero, and the magnitude of coefficients is quite similar for both countries (Table 5). However, most correlation coefficients between the person-specific residual of fertility equations and those of migration equations are not different from zero. Only correlation between the residual of fertility equations and that of migration to rural areas in Poland is positive (0.48) and significant. Thus, while unobserved determinants of childbearing are present among populations of both countries, people with specific fertility-related (read: fertility-raising) characteristics are over-represented only among migrants to rural areas in Poland. Controlling for unobserved fertility determinants of the two populations and the positive (unobserved) selection of migrants to rural areas in Poland does not change the coefficients of our main interest significantly (Tables 3 and 4, Model 4). The coefficients for rural migrants in Poland change compared to previous models, but not to a great extent. Still, migrants in rural areas now exhibit a significantly lower risk of 
first conception than non-migrants there. To sum up, our simultaneous analyses showed that rural-bound migrants in Poland are (to some degree) a selective group in their fertility preferences (or intentions), but most migrants in Austria and Poland change their behaviour in response to a change in the social context after residential relocation.

Let us finally study the childbearing patterns of migrants at destination in more detail. We extend our first and third models (the fourth model is very similar to the third one), allowing the intensity of conception to vary over time since arrival in the settlement. We focus on the risk of first conception only as changes over time are most interesting here and the number of events sufficient for a more detailed analysis. The results are presented in the graph in order to assist interpretation. Allowing the intensity of conception to vary over time improves the models (1) fit significantly (Austria: LR $=18.5$ with 4 df, p < 0.01; Poland: $\mathrm{LR}=469.8$ with $6 \mathrm{df}, \mathrm{p}<0.01$ ). Our analysis supports previous results on the high risk of first conception for migrants in all destinations (except in the large cities of Austria) (Figure 2). Moreover, the analysis reveals that the risk is particularly high immediately after migration and then gradually decreases, pointing thus to a strong inter-connection between migration, union formation and childbearing in Austria and Poland.

The second graph shows the fertility patterns for Austria and Poland after having controlled for the demographic and socio-economic selectivity of the migrants. Again, the model with time-varying intensity is significantly better than that where the risk is constant (Austria: LR $=5.8$ with $1 \mathrm{df}, \mathrm{p}<$ 0.05; Poland: $\mathrm{LR}=15.5$ with $4 \mathrm{df}, \mathrm{p}<0.01)$. As expected, the elevated risk of conception immediately after migration observed previously (almost) disappears completely when controlling for partnership status and union duration. The intensity of first conception for migrants to rural and small urban destination is now stable over time (Figure 3). Another and more interesting pattern common to both countries is a low risk of first conception for people who move to large cities. The drop in fertility levels, however, is a short-term one, and reaches by the end of the first year since residential relocation the 
levels characteristic for natives at destination. To sum up, our analysis of changing fertility patterns thus shows that people who move because of union formation exhibit elevated fertility levels after migration, whereas many of those who move to large cities (for reasons other than family formation) delay childbearing for a while, whatever their reasons. (A similar pattern would have also been expected for migrants to other destinations, but the model with constant risk turned out to be the best for them - except for migrants to rural areas in Poland, who displayed a specific fertility pattern.) Before we summarise and discuss our major results on migrant childbearing in Austria and Poland, we present our results on the effect of other variables.

\section{Impact of other variables}

The results on the effect of other variables correspond to patterns described in the literature, and we report them here briefly. In Austria, the intensity of first conception is the highest during the twenties, while in Poland it culminates in the first half of the twenties, thus confirming a relatively early start of childbearing in Eastern and Central Europe compared to the Western neighbours since the 1970s (Vikat 1994) (Table 6). As expected, union formation and marriage significantly increase the propensity of first conception. However, the rise is much larger and the subsequent decrease deeper for Poland, pointing to: first, a traditionally high share of single mothers in Austria (Prinz et al. 1998, 28-29) and a low proportion in Poland (Holzer and Kowalska 1997, 31); second, a very strong concentration of conceptions in the beginning of union in Poland (Oláh and Frątczak 2003a, 237). Concerning the effect of time, we notice decreasing first birth intensities in Austria from the mid-1960s to the late 1980s and an increase thenafter, while the risk in Poland at first increases and then remains stable. The Austrian pattern reflects the gradual postponement of childbearing there, which continued until the late 1980s (Coleman 1996, 21). 
The lower intensity of first conception during education intervals corresponds to expectations (Baizan et al. 2002, 39; Oláh and Frątczak 2003a, 237). A low risk of first conception for employed women in Austria and a relatively high risk for their counterparts in Poland are not surprising (cf. Kreyenfeld 2004, 302-303). The latter pattern results from the fact that in the context of full and compulsory employment, inactivity before childbearing obviously does indicate health problems (Kreyenfeld 2004, 301). The lower intensity of first conception for women with secondary and higher education in Poland corresponds to expectations (Oláh and Frątczak 2003a, 236). In Austria only women with secondary education have a relatively low risk. As expected, the larger the number of siblings, the higher the propensity to have the first child in both countries (Baizan et al. 2002, 39; Oláh and Frątczak 2003a, 236; Kreyenfeld 2004, 302-303). Religious people have somewhat lower first birth intensities compared to others in Poland, while this does not apply to Austria. A tendency of religious people to have either no children at all or many of them has also been observed in some other contexts (Katus et al. 2002, 175-177; cf. Kreyenfeld 2004, 303).

The intensity of second and third conception rises rapidly during the first year after previous birth and then decrease, as expected (Hoem et al. 2001a, 46; Oláh and Frątczak 2003b; cf. Vikat et al. 2004, 12). Interestingly, however, Austrian women seem to have somewhat shorter birth-intervals than their Polish counterparts (even after controlling for age). Second and third birth intensities decrease with age and union duration, and this is, again, not surprising. The propensity of second birth in Austria until the mid-1970s and third birth during the most observation period diminishes, as expected (Buber and Prskawetz 2000, 6; cf. Vikat et al. 2004, 12). Similarly, childbearing intensities in Poland have decreased since the mid-1980s (Holzer and Kowalska 1997, 11). The lower risk of childbearing during intervals in education and employment does not need to be commented here. The relatively high second and especially third birth intensities for highly educated women in Austria would require an explanation, however. Further analysis has shown that 
the patterns of elevated fertility for highly educated women disappear when controlling for their relative age at the start of childbearing and the educational attainment of their partner (Hoem 2001b, 257-258). Also, we see that the risk of second and third birth rises with increasing numbers of siblings and religiousness, which is, again, not surprising (Hoem et al. 2001a, 46; Oláh and Frątczak 2003b).

\section{Summary and discussion}

Let us now summarise the major results of our comparative study and discuss the role of migration in shaping the childbearing patterns of the two populations. First, our analysis showed significant variation in the fertility levels across settlement hierarchy both in Austria and Poland, as expected. Natives in urban areas in general and large cities in particular had a lower fertility compared to non-migrants in rural areas. Significant fertility differences across various settlements in both countries remained also when controlling for socio-demographic characteristics of population. A close look at the fertility patterns revealed that the variation in first birth risk was larger in Austria, while differences in second and third birth intensities were bigger in Poland.

Second, we observed a relatively high risk of first conception for the migrant population at all destinations in both countries (except the large cities of Austria), and the levels were particularly high in Poland. The elevated fertility for migrants disappeared, however, when controlling for partnership status and union duration, and migrants then displayed fertility levels similar to non-migrants at destination. Our analysis on second and third birth intensities showed that migrants exhibited fertility levels similar to those of natives at destination across all models for both countries. Subsequent simultaneous analyses revealed the presence of unobserved selectivity for movers to rural areas in Poland. This discovery changed our main results to a very little and insignificant extent (the risk of conception for migrants to rural areas in 
previous models was slightly overestimated). Besides showing similar fertility levels for movers and stayers at destination in general, our analysis also points to some exceptions. Migrants from the large cities had a relatively low second birth risk at all destinations in Poland, whereas migrants from the rural areas had surprisingly low third birth intensities in Austria. In addition, the third birth risk was relatively low for all migrants in rural areas in the same country. Finally, a closer look at the changing patterns of first conception intensities showed a short-term drop in the risk levels for people who moved to the large cities.

Let us now discuss the causes behind the observed patterns, starting with decreasing fertility levels across the settlement hierarchy. Why are the fertility levels lower in urban areas in general and in large cities in particular? At least three (partly competing and in part complementary) explanations can be offered. First, most people in rural settlements both in Austria and Poland live in single family houses, while in urban areas, especially in large cities, flats in multi-storey dwellings are the dominant feature (SA 2003). Living space in family houses is usually large (cf. Kulu 2003b). Thus, differences in housing type and size may account for varying fertility levels across the settlement hierarchy. Second, differences in other resources and costs may also play a role. While the direct economic costs of child-raising may vary across settlements within the context of a market economy (Austria) more so than a planned economy (Poland), the differences in opportunity costs were significant in both cases. Clearly, in urban areas, especially in large cities, wider (work or leisure-related) opportunities open up. Having children, however, often means that the possibility of taking these opportunities is rather small, if not redundant at all. Third, varying norms and values across settlements should be stressed. Research has shown that life in rural settlement is more 'traditional' and the notion of family still stronger. What is more, the rural population can be considered a major 'regional sub-culture', distinct from urban ones (cf. Lesthaeghe and Neels 2002). 
Our research does not provide an answer to the question which of the three factors (if any) is the most important in accounting for changing fertility levels across various settlements in both countries. It nevertheless shows that internal migrants, whatever their origin, adopt the fertility behaviour prevalent at destination because of a change in context. As the risk of first conception for migrants rather quickly followed that of natives at destination, one may argue that economic factors are more important than cultural ones. However, the differences in first birth intensities across various settlements were not very large (even in Austria), and the number of events not enough to draw detailed conclusions on varying fertility levels for migrants at destination. While migrant adaptation (whatever the reasons) is a major result of our research, it also points to a socialisation-effect. However, we were not able to analyse this effect in detail because the impact of childhood residence for migrants was significant only in two models out of six. Whether the 'outliers' reflect some specific conditions or point to a 'real' (and more universal) socialisation-effect will remain an issue for further research.

The elevated risk of first conception for migrants to rural and small urban areas in both countries is not surprising: Many migrations to rural settlements and towns are driven by union formation, while other reasons are mostly behind the moves to large cities. Thus, we observed selectivity of migrants by childbearing intentions. This selectivity was easy to capture including partnership status and union duration in the models. (The reason behind migration did further control for this selectivity.) At first sight, a by far higher risk of first conception for migrants in Poland, especially in towns and cities, seems to support the importance of housing policies specific to planned economies in shaping childbearing patterns. However, the difference across countries we observed may mostly stem from the fact that the Polish data contained more local moves than did the Austrian one $\mathrm{e}^{5}$. Another factor to consider is the presence of unobserved selectivity for migrants to rural areas in Poland. Further analysis revealed that behind this pattern were mostly women who first moved, then conceived a child and only thenafter entered union (if at 
all). While some of them were moving with union formation in mind, others may have not (yet) planned pregnancy and subsequent union. The reason for observing such a pattern among rural and not small urban migrants remains unclear. Maybe contraceptive practices are less efficient in rural areas.

Finally, let us turn to the disruption effect we observed for migrants to large cities both in Austria and Poland. While postponement of childbearing due to residential relocation may be a natural option for most movers, it is much more difficult to explain why only migrants to large cities and not to other areas experienced the disruption-effect. We believe that two factors may account for this. First, compositional differences possibly still play a role. In our analyses, we controlled for the fact that people moving for family reasons were over-represented in rural and small urban destinations, and that those moving for other reasons were more numerous in the cities. However, we were not able to study if the patterns for movers with various reasons were different at the same destination. If this were the case, then our average patterns should be closer to the behaviour of the dominant group(s) at destination. Second, the city context certainly has its own effects. Settling in a large city requires great efforts, as opportunities to consider are wide and difficult to estimate beforehand. As a result, first housing for newcomers is often short-term only (Clark and Huang 2003). Moreover, people who come from smaller places may intentionally direct all their energy to quickly adjusting to city life during the first months or year after arrival.

Our study thus showed significant variation in the fertility levels across the settlement hierarchy, and that people who moved from one settlement to another adopted the fertility behaviour dominant at destination. We also found evidence for an elevated first birth risk for women who changed their residence because of union formation, and for a short-term postponement of childbearing for those who moved to a large city. When comparing patterns across countries, the results are quite similar, despite slightly different fertility and migration histories and a post-war societal context that differed between the two countries. (Previous research has shown similar fertility patterns also for 
internal migrants in Estonia (Kulu 2003a).) This is not surprising, as similar variations in the economic and cultural determinants of fertility across settlements do exist both in Austria and Poland, and migrants therefore experienced rather similar changes. One notable difference between the countries that requires brief discussion is the fact that the risk of first birth varied across the settlement hierarchy more so in Austria than in Poland, whereas differences in second and third birth intensities were larger in Poland. The transition to first child was thus spatially more selective in Austria, while that to second and third child was in Poland. Whether the difference did result from country- or wider system-specific factors remains to be seen. We can only add to the question by asking why women in urban areas, especially in large cities, were prone to staying childless in Austria, while in Poland most of them gave a birth to one child at least.

Future research on internal migrant fertility should focus on at least two interrelated topics: First, information on housing conditions. This would enable deeper insight into determinants of varying fertility levels across settlement hierarchy and the causes behind the fertility adaptation of migrants. Second, the effect of sub- and counter-urban moves on childbearing behaviour. While urbanisation undoubtedly has been a factor that promoted decreasing fertility levels in many developed countries, extending sub-urbanisation may be a key (if any) leading to rising fertility levels in Europe. 


\section{Acknowledgements}

I am grateful to Andres Vikat for valuable comments and suggestions, and Susann Backer for editing the English of the manuscript. I also thank the Austrian Institute for Family Studies and Martin Spielauer for providing me with the original Austrian FFS data, and the Institute of Statistics and Demography of Warsaw School of Economics and Ewa Fratczak for the permission to use the original Polish FFS data. Kamil Sienkiewicz contributed to constructing educational histories of the Polish women.

\section{Notes}

${ }^{1}$ - Official data on urban-rural fertility differentials in Austria were not available to this study. Our estimates of the TFR across Austrian settlements are based on information available on the Austrian province Oberösterreich and our own calculations using the Austrian FFS data. (The latter, however, does not allow us to differentiate to great detail between rural settlements and small towns. For information on changing fertility across settlements (and districts) in Oberösterreich, see AOL 2003, 18.)

${ }^{2}$ - Ideally we would have a separate category for the capital (or the largest) city, but the information is not available for Poland. As our study is of a comparative nature, we gave up the idea of having a separate category for the capital city just for Austria. Our preliminary analysis showed that the loss of information was not significant if we kept the capital city of Vienna together with other major cities in Austria (Graz, Linz, Salzburg and Innsbruck).

${ }^{3}$ - However, the category 'rural' also covers the smallest towns, mostly those with a population below 10,000. Our various experiments (with the size, density and sectoral composition of the populations) showed that the rural areas could not be distinguished from the smallest towns in Austria when information on migration origin and destination was available at the level of district and not commune. Thus, the variable constructed does not reflect the official urban-rural-distinction in every detail, but nevertheless captures the "degree of urbanisation' of settlements of origin and destination rather well.

${ }^{4}$ - The reason behind considering destination and not the origin of migration will become clear in the course of the data analysis.

${ }^{5}$ - Specific childbearing patterns for marriage-migrants in Poland (if existent) may also result from poor access to modern contraceptives within the context of a planned economy. 


\section{References}

Andersson, G. 2004. Childbearing after migration: fertility patterns of foreign-born women in Sweden, International Migration Review 38(1) (in press).

AOL (Amt der oberösterreichischen Landesregierung). 2003. Geburten- und Fruchtbarkeitsentwicklung in Oberösterreich 1960-1995. Linz: Amt der oberösterreichischen Landesregierung.

Baizan, P., A. Aassve, and F. C. Billari. 2002. Institutional arrangements and life course outcomes: the interrelations between cohabitation, marriage and first birth in Germany and Sweden, MPIDR Working Paper 2002-026. Rostock: Max Planck Institute for Demographic Research.

Bourdieu, P. 1990. The Logic of Practice. Stanford: Stanford University Press.

Brockeroff, M. 1995. Fertility and family-planning in African cities: the impact of female migration, Journal of Biosocial Science 27(3): 347-358.

Brockeroff, M., and X. S. Yang. 1994. Impact of migration on fertility in Sub-Saharan Africa, Social Biology 41(1-2): 19-43.

Buber, I., and A. Prskawetz. 2000. Current demographic trends in Austria, in T. Kučera, O. Kučerová, O. Opara and E. Schaich (eds.), New Demographic Faces of Europe. Berlin: Springer-Verlag, pp. 1-27.

Buckley, C. 1995. The myth of managed migration: migration control and market in the Soviet period, Slavic Review 54: 896-916.

Carlson, E. D. 1985. The impact of international migration upon the timing of marriage and childbearing, Demography 22(1): 61-72.

Champion, A. G. 1993. Geographical distribution and urbanization, in D. Noin and R. Woods (eds.), The Changing Population of Europe. Oxford: Blackwell Publishers, pp. 23-37.

Champion, A. G. 2001. Urbanization, sub-urbanization, counterurbanization, and reurbanization, in R. Paddison (ed.), Handbook of Urban Studies. London: Sage Publications, pp. 143-161.

Chesnais, J.-C. 1992. The Demographic Transition: Stages, Patterns, and Economic Implications. Oxford: Clarendon Press.

Clark, W. A. V., and Y. Huang. 2004. Linking migration and mobility: individual and contextual effects in British housing markets, Regional Studies 38(6) (in press).

Coleman, D. 1996. New patterns and trends in European fertility: international and subnational comparisons, in D. Coleman (ed.), Europe's Population in the 1990s. Oxford: Oxford University Press, pp. 1-61.

Courgeau, D. 1989. Family formation and urbanization, Population: An English Selection 44(1): 123-146.

Duncan, O. D. 1965. Farm background and differential fertility, Demography 2: 240-249.

Easterlin, R. A. 1980. Birth and Fortune: The Impact of Numbers on Personal Welfare. New York: Basic Books.

Farber, S. C., and B. S. Lee. 1984. Fertility adaptation of rural-to-urban migrant women: a method of estimation applied to Korean women, Demography 21(3): 339-345.

Freedman, R. and D. P. Slesinger. 1961. Fertility differentials for the indigenous non-farm population of the United States, Population Studies 15(2): 161-173.

Fuchs, I. 1997. Stadtregionen 1991 - das Konzept, Statistische Nachrichten 2: 76-83.

Goldberg, D. 1959. The fertility of two-generation urbanites, Population Studies 12(3): 214-222.

Goldstein, S. 1973. Interrelations between migration and fertility in Thailand, Demography 10(2): 225-241.

Goldstein, S., and A. Goldstein. 1981. The impact of migration on fertility: an 'own children' analysis for Thailand, Population Studies 35(2): 265-281.

Hervitz, H. M. 1985. Selectivity, adaptation, or disruption? A comparison of alternative hypotheses on the effects of migration on fertility: the case of Brazil, International Migration Review 19(2): 293-317.

Hoem, J. M. 1975. Fertility and out-migration: reflections on research approaches in 
empirical investigations of the association between two demographic phenomena, Working Paper 1. Copenhagen: University of Copenhagen, Laboratory of Actuarial Mathematics.

Hoem, J. M. 1993. Classical demographic models of analysis and modern event-history techniques, Stockholm Research Reports in Demography 75. Stockholm: Stockholm University, Demography Unit.

Hoem, J. M. 1995. Harmless omission in the standardization of vital rates, European Journal of Population 11: 313-322.

Hoem, J. M., G. Neyer, and A. Prskawetz. 2001a. Autonomy or conservative adjustment? The effect of public policies and educational attainment on third births in Austria, MPIDR Working Paper 2001-016. Rostock: Max Planck Institute for Demographic Research.

Hoem, J. M., G. Neyer, and A. Prskawetz. 2001b. Autonomy or conservative adjustment? The effect of public policies and educational attainment on third births in Austria, Population Studies 55(3): 249-261.

Holzer, J. Z., and I. Kowalska. 1997. Fertility and Family Surveys in Countries of the ECE Region: Standard Country Report, Poland. New York: United Nations.

Kahn, J. R. 1994. Immigrant and native fertility during the 1980s: adaptation and expectations for the future, International Migration Review 28(3): 501-519.

Katus, K., A. Puur, and A. Pôldma. 2002. Eesti pôlvkondlik rahvastikuareng [Population Development in Estonia across Generations], Rahvastiku-uuringud D 2. Tallinn: Eesti Kôrgkoolidevaheline Demouuringute Keskus.

Kok, H. 1999. Migration from the city to the countryside in Hungary and Poland, GeoJournal 49: 53-62.

Kreyenfeld, M. 2002. Time-squeeze, partner effect or self-selection? An investigation into the positive effect of women's education on second birth risks in West Germany, Demographic Research 7(2): 13-48.

Kreyenfeld, M. 2004. Fertility decisions in the FRG and GDR: an analysis with data from the German Fertility and Family Survey, Demographic Research S3: 273-318.

Kulu, H. 2003a. Migration and fertility: competing hypotheses re-examined, MPIDR Working Paper WP-2003-035. Rostock: Max Planck Institute for Demographic Research.

Kulu, H. 2003b. Housing differences in the late Soviet city: the case of Tartu, Estonia. International Journal of Urban and Regional Research 27(4): 897-911.

Kupiszewski, M., H. Durham, and P. Rees. 1998. Internal migration and urban change in Poland, European Journal of Population 14: 265-290.

Lee, B. S. 1992. The influence of rural-urban migration on migrant's fertility behavior in Cameroon, International Migration Review 26(4): 1416-1447.

Lee, B. S., and L. G. Pol. 1993. The influence of rural-urban migration on migrants fertility in Korea, Mexico and Cameroon, Population Research and Policy Review 12(1): 3-26.

Lesthaeghe, R., and K. Neels. 2002. From the first to the second demographic transition: an interpretation of the spatial continuity of demographic innovation in France, Belgium and Switzerland, European Journal of Population 18(4):325-360.

Lillard, L. A. 1993. Simultaneous equations for hazards: marriage duration and fertility timing, Journal of Econometrics 56(1-2): 189-217.

Lillard, L. A., M. J. Brien, and L. J. Waite. 1995. Premarital cohabitation and subsequent marital dissolution: a matter of self-selection, Demography 32(3): 437-457.

Lindstrom, D. P. 2003. Rural-urban migration and reproductive behavior in Guatemala, Population Research and Policy Review 22: 351-372.

Lutz, W., S. Scherbov, and A. Hanika. 2003. "Vienna: a city beyond aging" - revisited and revised, Vienna Yearbook of Population Research 2003: 181-195.

Macisco, J. J., L. F. Bouvier, and R. H. Weller. 1970. The effect of labor force participation on the relation between migration status and fertility in San Juan, Puerto Rico, Milbank Memorial Fund Quarterly 48(1): 51-70.

Macura, M., and A. L. MacDonald. 2003. Fertility and fertility regulation in Eastern Europe: from the socialist to the post-socialist era, in I. E. Kotowska and J. Jóźwiak (eds.), 
Population of Central and Eastern Europe: Challenges and Opportunities. Warsaw: Statistical Publishing Establishment, pp. 35-90.

Michielin, F. 2002. Lowest low fertility in an urban context: when migration plays a key role, MPIDR Working Paper 2002-050. Rostock: Max Planck Institute for Demographic Research.

Mulder, C. H., and M. Wagner. 2001. The connection between family formation and first-time home ownership in the context of West Germany and the Netherlands, European Journal of Population 17(2): 137-164.

Murphy, M. J., and O. Sullivan. 1985. Housing tenure and family formation in contemporary Britain, European Sociological Review 1(3): 230-243.

Myers, G. C., and E. W. Morris. 1966. Migration and fertility in Puerto Rico, Population Studies 20(1): 85-96.

Oláh, L. Sz., and E. Fratczak. 2003a. Gendering family formation: first marriage and first birth in Hungary and Poland, in I. E. Kotowska and J. Jóźwiak (eds.), Population of Central and Eastern Europe: Challenges and Opportunities. Warsaw: Statistical Publishing Establishment, pp. 219-249.

Oláh, L. Sz., and E. Fratczak. 2003b. First and second births in first marriage in Hungary and Poland: a comparative analysis based on FFS-data, Paper presented at the European Population Conference 2003 in Warsaw in Poland.

Prinz, C., W. Lutz, V. Nowak, and C. Pfeiffer. 1998. Fertility and Family Surveys in Countries of the ECE Region: Standard Country Report, Austria. New York: United Nations.

Rosenwaite, I. 1973. Two generations of Italians in America: their fertility experience, International Migration Review 7(3): 271-280.

Rundquist, F.-M., and L. A. Brown. 1989. Migrant fertility differentials in Ecuador, Geografiska Annaler B 71(2): 109-123.

Rykiel, Z., and I. Jażdżewska. 2002. The maturing of the Polish urban system, in H. S. Geyer (ed.), International Handbook of Urban Systems. Cheltenham: Edward Elgar, pp. 271-294.

SA (Statistik Austria). 2003. Ein Blick auf die Gemeinde. Wien: Statistik Austria.

SA (Statistik Austria). 2004a. Statistisches Jahrbuch 2004. Wien: Statistik Austria.

SA (Statistik Austria). 2004b. Wanderungsbilanz: 1934-1951, 1951-1961, 1961-1971, 1971-1981, 1981-1991, 1991-2001. http://www.statistik.at/karten/themen.shtml.

Sauberer, M. 1981. Migration and Settlement: 10. Austria. Laxenburg: IIASA

Singley, S. G., and N. S. Landale. 1998. Incorporating origin and process in migration-fertility frameworks: the case of Puerto Rican women, Social Forces 76(4): $1437-1464$.

Stephen, E. H., and F. D. Bean. 1992. Assimilation, disruption and the fertility of Mexican-origin women in the United States, International Migration Review 26(1): $67-88$.

UN (United Nations). 2002. World Urbanization Prospects: The 2001 Revision. New York: United Nations.

Vikat, A. 1994. Family Formation in Estonia, Publications of the Finnish Demographic Society 15. Helsinki: Finnish Demographic Society.

Vikat, A., E. Thomson, and A. Prskawetz. 2004. Childrearing responsibility and stepfamily fertility in Finland and Austria, European Journal of Population 20: 1-21.

Vojtěchovská, P. 2000. Population development in Poland, in T. Kučera, O. Kučerová, O. Opara and E. Schaich (eds.), New Demographic Faces of Europe. Berlin: Springer-Verlag, pp. 247-266.

White, M. L., L. Moreno, and S. Guo. 1995. The interrelation of fertility and geographic mobility in Peru: a hazards model analysis, International Migration Review 29(2): $492-514$. 
Table 1. Basic information on the Austrian and Polish FFS female samples.

\begin{tabular}{|lcc|}
\hline & Austria & Poland \\
\hline Survey year & $1995-96$ & 1991 \\
Age range of respondents & $20-54$ & $18-49$ \\
Sample size & 4581 & 4209 \\
Response rate & $72 \%$ & $95 \%$ \\
Research population & 3980 & 4109 \\
Reasons for exclusion: & & \\
$\quad$ Foreign-born or abroad at age 15 & 403 & - \\
Incomplete data or other & 198 & 100 \\
\hline
\end{tabular}

Source: Holzer and Kowalska 1997; Prinz et al. 1998. 
Table 2. Person-months (exposures) and births (occurrences) across residential categories in Austria and Poland.

\begin{tabular}{|c|c|c|c|c|c|c|c|c|c|c|c|c|}
\hline & \multicolumn{5}{|c|}{ Austria } & \multicolumn{7}{|c|}{ Poland } \\
\hline & First birth & & Second birth & & Third birth & & First birth & & Second birth & & Third birth & \\
\hline & $\begin{array}{l}\text { Person- } \\
\text { months }\end{array}$ & Births & $\begin{array}{l}\text { Person- } \\
\text { months }\end{array}$ & Births & $\begin{array}{l}\text { Person- } \\
\text { months }\end{array}$ & Births & $\begin{array}{l}\text { Person- } \\
\text { months }\end{array}$ & Births & $\begin{array}{l}\text { Person- } \\
\text { months }\end{array}$ & Births & $\begin{array}{l}\text { Person- } \\
\text { months }\end{array}$ & Births \\
\hline Non-migrants in rural areas & 190505 & 1348 & 47899 & 736 & 64923 & 275 & 142465 & 915 & 20289 & 496 & 32168 & 234 \\
\hline Rural migrants in rural areas & 14191 & 215 & 14803 & 245 & 26378 & 85 & 8666 & 304 & 15785 & 390 & 26583 & 216 \\
\hline Small town migrants in rural areas & 2556 & 46 & 2133 & 40 & 3145 & 20 & 1682 & 57 & 2625 & 68 & 5014 & 39 \\
\hline Large city migrants in rural areas & 4782 & 56 & 3837 & 59 & 5449 & 20 & 510 & 17 & 1106 & 17 & 1165 & 5 \\
\hline Migrants (no origin) in rural areas & 705 & 8 & 623 & 8 & 1410 & 2 & & & & & & \\
\hline Non-migrants in small towns & 62412 & 383 & 14243 & 217 & 18802 & 66 & 110102 & 651 & 23271 & 295 & 22385 & 77 \\
\hline Rural migrants in small towns & 8052 & 104 & 4805 & 75 & 6001 & 37 & 10269 & 198 & 13270 & 211 & 22770 & 91 \\
\hline Small town migrants in small towns & 4266 & 66 & 3761 & 52 & 4094 & 29 & 9109 & 200 & 13147 & 204 & 18124 & 74 \\
\hline Large city migrants in small towns & 953 & 17 & 708 & 10 & 1129 & 7 & 788 & 23 & 2315 & 27 & 1805 & 7 \\
\hline Migrants (no origin) in small towns & 435 & 4 & 148 & 2 & 267 & 0 & & & & & & \\
\hline Non-migrants in large cities & 78940 & 445 & 23045 & 246 & 23078 & 52 & 84561 & 454 & 20603 & 203 & 15713 & 55 \\
\hline Rural migrants in large cities & 25569 & 207 & 10773 & 120 & 10251 & 22 & 7589 & 103 & 7509 & 91 & 11439 & 22 \\
\hline Small town migrants in large cities & 5431 & 32 & 1980 & 19 & 1306 & 6 & 9110 & 103 & 8104 & 71 & 6010 & 10 \\
\hline Large city migrants in large cities & 3994 & 27 & 2224 & 18 & 2387 & 9 & 9560 & 123 & 14753 & 104 & 11473 & 27 \\
\hline Migrants (no origin) in large cities & 665 & 12 & 339 & 6 & 989 & 0 & & & & & & \\
\hline Total & 403454 & 2970 & 131320 & 1853 & 169606 & 630 & 394410 & 3148 & 142776 & 2177 & 174648 & 857 \\
\hline
\end{tabular}


Table 3. Effect of residence and migration on intensity of conception leading to birth in Austria (relative risks).

\begin{tabular}{|c|c|c|c|c|}
\hline & Model 1 & Model 2 & Model 3 & Model 4 \\
\hline \multicolumn{5}{|l|}{ First conception } \\
\hline \multicolumn{5}{|l|}{ Current residence } \\
\hline Non-migrants in rural areas & 1 & 1 & 1 & 1 \\
\hline Migrants in rural areas & $1.33 * * *$ & 1.05 & 0.95 & 0.87 \\
\hline Non-migrants in small towns & $0.82 * * *$ & $0.80 * * *$ & $0.85 * * *$ & $0.80 * * *$ \\
\hline Migrants in small towns & $1.21 * *$ & 0.91 & $0.84 *$ & $0.77 *$ \\
\hline Non-migrants in large cities & $0.70 * * *$ & $0.63 * * *$ & $0.69 * * *$ & $0.64 * * *$ \\
\hline Migrants in large cities & $0.70 * * *$ & $0.62 * * *$ & $0.67 * * *$ & $0.57 * * *$ \\
\hline \multicolumn{5}{|c|}{ Number of migrations (for migrants) } \\
\hline 1 migration & & & 1 & 1 \\
\hline $2+$ migrations & & & $1.19 * *$ & 1.19 \\
\hline \multicolumn{5}{|c|}{ Reason for migration (for migrants) } \\
\hline Other & & & 1 & 1 \\
\hline Family & & & $1.15 *$ & $1.23 * *$ \\
\hline Housing & & & 0.83 & 0.83 \\
\hline \multicolumn{5}{|l|}{ Second conception } \\
\hline \multicolumn{5}{|l|}{ Current residence } \\
\hline Non-migrants in rural areas & 1 & 1 & 1 & 1 \\
\hline Migrants in rural areas & $1.14 * *$ & 1.11 & 1.11 & 1.02 \\
\hline Non-migrants in small towns & 1.07 & 1.07 & 1.07 & 1.07 \\
\hline Migrants in small towns & 1.07 & 1.07 & 1.07 & 1.03 \\
\hline Non-migrants in large cities & $0.79 * * *$ & $0.79 * * *$ & $0.85 * *$ & $0.76 * * *$ \\
\hline Migrants in large cities & $0.82 * *$ & $0.84 *$ & 0.89 & $0.78 *$ \\
\hline \multicolumn{5}{|c|}{ Number of migrations (for migrants) } \\
\hline 1 migration & & & 1 & 1 \\
\hline $2+$ migrations & & & 1.01 & 0.99 \\
\hline \multicolumn{5}{|l|}{ Third conception } \\
\hline \multicolumn{5}{|l|}{ Current residence } \\
\hline Non-migrants in rural areas & 1 & 1 & 1 & 1 \\
\hline Migrants in rural areas & 0.84 & $0.81 *$ & $0.76 * *$ & $0.72 * *$ \\
\hline Non-migrants in small towns & 0.82 & 0.82 & 0.83 & 0.81 \\
\hline Migrants in small towns & 1.27 & 1.26 & 1.06 & 1.01 \\
\hline Non-migrants in large cities & $0.64 * * *$ & $0.66 * * *$ & $0.73 *$ & $0.65 * *$ \\
\hline Migrants in large cities & $0.64 * *$ & $0.63 * *$ & $0.61 * *$ & $0.53 * * *$ \\
\hline \multicolumn{5}{|c|}{ Residence at age 15 (for migrants) } \\
\hline Rural area & 1 & 1 & 1 & 1 \\
\hline Small town & $1.60 * * *$ & $1.63 * * *$ & $1.62 * * *$ & $1.79 * * *$ \\
\hline Large city & 1.35 & $1.44 *$ & $1.45 *$ & $1.45 *$ \\
\hline \multicolumn{5}{|c|}{ Number of migrations (for migrants) } \\
\hline 1 migration & & & 1 & 1 \\
\hline $2+$ migrations & & & 1.22 & 1.17 \\
\hline
\end{tabular}

Significance: ' $*$ ' $=10 \%$; $^{\prime * *}=5 \%$; ‘***’ $=1 \%$. 
Table 4. Effect of residence and migration on intensity of conception leading to birth in Poland (relative risks).

\begin{tabular}{|c|c|c|c|c|}
\hline & Model 1 & Model 2 & Model 3 & Model 4 \\
\hline \multicolumn{5}{|l|}{ First conception } \\
\hline \multicolumn{5}{|l|}{ Current residence } \\
\hline Non-migrants in rural areas & 1 & 1 & 1 & 1 \\
\hline Migrants in rural areas & $3.33 * * *$ & 1.04 & 0.94 & $0.79 * *$ \\
\hline Non-migrants in small towns & $0.89 * *$ & 0.92 & 1.02 & 1.02 \\
\hline Migrants in small towns & $2.16 * * *$ & 0.97 & 0.99 & 0.98 \\
\hline Non-migrants in large cities & $0.74 * * *$ & $0.65 * * *$ & $0.80 * * *$ & $0.78 * * *$ \\
\hline Migrants in large cities & $1.22 * * *$ & $0.65 * * *$ & $0.73 * * *$ & $0.70 * * *$ \\
\hline \multicolumn{5}{|c|}{ Number of migrations (for migrants) } \\
\hline 1 migration & & & 1 & 1 \\
\hline $2+$ migrations & & & 0.98 & 0.93 \\
\hline \multicolumn{5}{|c|}{ Reason for migration (for migrants) } \\
\hline Other & & & 1 & 1 \\
\hline Family & & & 1.09 & 1.10 \\
\hline Housing & & & $1.32 * *$ & $1.35 * *$ \\
\hline \multicolumn{5}{|l|}{ Second conception } \\
\hline \multicolumn{5}{|l|}{ Current residence } \\
\hline Non-migrants in rural areas & 1 & 1 & 1 & 1 \\
\hline Migrants in rural areas & $1.12 *$ & $1.12 *$ & 1.09 & 0.94 \\
\hline Non-migrants in small towns & $0.59 * * *$ & $0.59 * * *$ & $0.67 * * *$ & $0.62 * * *$ \\
\hline Migrants in small towns & $0.84 * *$ & $0.85 * *$ & $0.86 *$ & 0.87 \\
\hline Non-migrants in large cities & $0.51 * * *$ & $0.51 * * *$ & $0.60 * * *$ & $0.54 * * *$ \\
\hline Migrants in large cities & $0.61 * * *$ & $0.63 * * *$ & $0.66 * * *$ & $0.63 * * *$ \\
\hline \multicolumn{5}{|c|}{ Residence at age 15 (for migrants) } \\
\hline Rural area & 1 & 1 & 1 & 1 \\
\hline Small town & 0.89 & $0.88 *$ & 0.93 & 0.89 \\
\hline Large city & $0.68 * * *$ & $0.68 * * *$ & $0.77 * *$ & $0.70 * * *$ \\
\hline \multicolumn{5}{|c|}{ Number of migrations (for migrants) } \\
\hline 1 migration & & & 1 & 1 \\
\hline $2+$ migrations & & & 1.09 & 1.02 \\
\hline \multicolumn{5}{|l|}{ Third conception } \\
\hline \multicolumn{5}{|l|}{ Current residence } \\
\hline Non-migrants in rural areas & 1 & 1 & 1 & 1 \\
\hline Migrants in rural areas & 1.09 & 1.04 & 1.10 & 0.93 \\
\hline Non-migrants in small towns & $0.50 * * *$ & $0.49 * * *$ & $0.54 * * *$ & $0.49 * * *$ \\
\hline Migrants in small towns & $0.68 * * *$ & $0.66 * * *$ & $0.70 * * *$ & $0.68 * * *$ \\
\hline Non-migrants in large cities & $0.55 * * *$ & $0.57 * * *$ & $0.67 * * *$ & $0.59 * * *$ \\
\hline Migrants in large cities & $0.38 * * *$ & $0.38 * * *$ & $0.41 * * *$ & $0.35 * * *$ \\
\hline \multicolumn{5}{|c|}{ Number of migrations (for migrants) } \\
\hline 1 migration & & & 1 & 1 \\
\hline $2+$ migrations & & & 1.10 & 1.03 \\
\hline
\end{tabular}

Significance: ' $*$ ' $=10 \%$; $^{\prime * * ’}=5 \%$; ‘***’ $=1 \%$. 
Table 5. Standard deviations and correlations between person-specific residuals.

\begin{tabular}{|lcc|}
\hline & Austria & Poland \\
\cline { 2 - 3 } & Model 4 & Model 4 \\
\hline Standard deviations & $0.690 * * *$ & $0.435 * * *$ \\
Fertility & $0.969 * * *$ & $0.976 * * *$ \\
Migration to rural areas & $1.223 * * *$ & $1.306 * * *$ \\
Migration to small towns & $1.430 * * *$ & $1.198 * * *$ \\
Migration to large cities & & \\
Correlations & 0.155 & $0.484 * * *$ \\
Fertility and migration to rural areas & 0.066 & 0.025 \\
Fertility and migration to small towns & 0.072 & 0.084 \\
\hline Fertility and migration to large cities & & \\
\hline
\end{tabular}

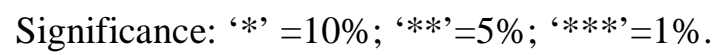

a - Correlations between the person-specific residuals of three migration equations were also estimated, but are not presented here. 
Table 6. Effect of control variables on intensity of conception leading to birth in Austria and Poland (parameter estimates and relative risks).

\begin{tabular}{|c|c|c|c|c|}
\hline & Austria & & Poland & \\
\hline & Model 3 & Model 4 & Model 3 & Model 4 \\
\hline First conception & & & & \\
\hline Linear splines & & & & \\
\hline Constant (baseline) & $-3.583 * * *$ & $-3.813 * * *$ & $-5.256 * * *$ & $-5.419 * * *$ \\
\hline Age (baseline) & & & & \\
\hline 15-19 years (slope) & $0.417 * * *$ & $0.470 * * *$ & $0.536 * * *$ & $0.545 * * *$ \\
\hline 20-24 years (slope) & 0.005 & $0.057 * * *$ & -0.004 & 0.023 \\
\hline 25-29 years (slope) & 0.019 & $0.055 * * *$ & $-0.074 * * *$ & $-0.061 * * *$ \\
\hline $30+$ years (slope) & $-0.131 * * *$ & $-0.111 * * *$ & $-0.123 * * *$ & $-0.125 * * *$ \\
\hline Cohabitation $(\mathrm{ref}=\mathrm{single})$ & & & & \\
\hline Enter cohabitation (constant) & $1.374 * * *$ & $1.393 * * *$ & $2.465 * * *$ & $2.453 * * *$ \\
\hline $0-1$ years (slope) & $-0.567 * * *$ & $-0.518 * * *$ & $-0.708 * *$ & $-0.580 *$ \\
\hline $2-3$ years (slope) & 0.016 & 0.023 & $-0.318 *$ & $-0.302 *$ \\
\hline $4+$ years (slope) & 0.004 & 0.013 & 0.013 & 0.006 \\
\hline Marriage (ref=cohabitant) & & & & \\
\hline Enter marriage (constant) & $0.780 * * *$ & $0.770 * * *$ & $0.726 * * *$ & $0.753 * * *$ \\
\hline $0-1$ years (slope) & 0.104 & 0.224 & -0.125 & -0.085 \\
\hline $2-3$ years (slope) & $-0.118 *$ & -0.034 & -0.115 & -0.079 \\
\hline 4+ years (slope) & $-0.163 * * *$ & $-0.158 * * *$ & $-0.172 * * *$ & $-0.160 * * *$ \\
\hline Year & & & & \\
\hline-1974 (slope) & $-0.022 * * *$ & $-0.026 * * *$ & $0.033 * * *$ & $0.037 * * *$ \\
\hline 1975-84 (slope) & $-0.025 * * *$ & $-0.031 * * *$ & 0.007 & 0.009 \\
\hline $1985+$ (slope) & $0.028 * * *$ & $0.029 * * *$ & 0.003 & 0.005 \\
\hline Categorical variables & & & & \\
\hline Education enrollment & & & & \\
\hline Not enrolled & 1 & 1 & 1 & 1 \\
\hline Enrolled & $0.44 * * *$ & $0.44 * * *$ & $0.43 * * *$ & $0.42 * * *$ \\
\hline Education level & & & & \\
\hline Basic & 1 & 1 & 1 & 1 \\
\hline Secondary & $0.69 * * *$ & $0.60 * * *$ & $0.81 * * *$ & $0.75 * * *$ \\
\hline Higher & 1.01 & 0.86 & $0.81 * *$ & $0.69 * * *$ \\
\hline Employment status & & & & \\
\hline Not employed & 1 & 1 & 1 & 1 \\
\hline Employed & $0.77 * * *$ & $0.73 * * *$ & $1.10 *$ & $1.10 *$ \\
\hline Number of siblings & & & & \\
\hline $0-1$ & 1 & 1 & 1 & 1 \\
\hline 2 & $1.19 * * *$ & $1.21 * * *$ & $1.10 *$ & $1.11 *$ \\
\hline $3+$ & $1.32 * * *$ & $1.38 * * *$ & $1.26 * * *$ & $1.30 * * *$ \\
\hline Religiousness & & & & \\
\hline No & 1 & 1 & 1 & 1 \\
\hline Somewhat & 1.03 & 1.02 & $0.90 * *$ & $0.88 * * *$ \\
\hline Very & 0.97 & 0.92 & $0.90 *$ & $0.88 *$ \\
\hline
\end{tabular}


Table 6. (continued).

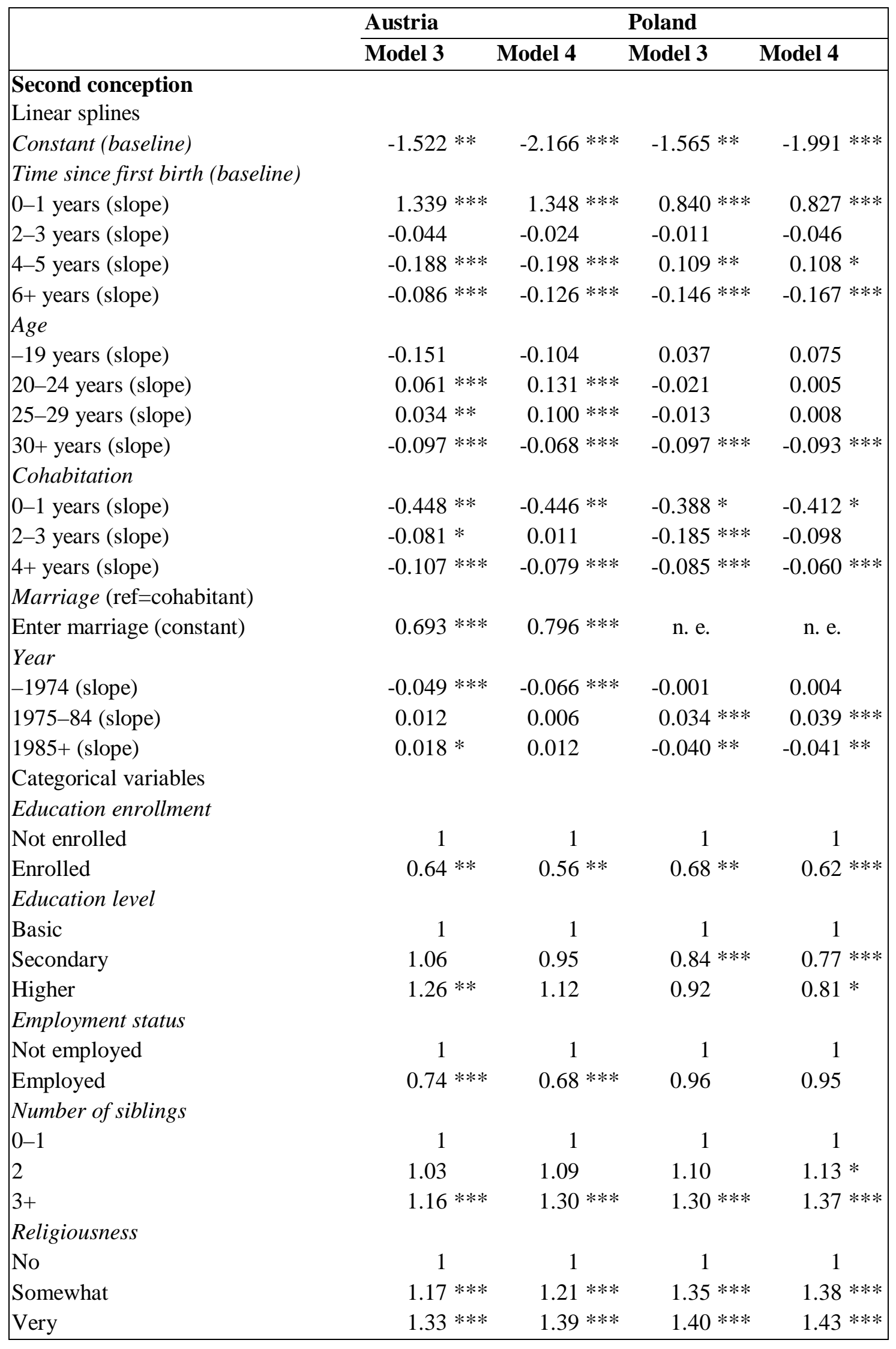


Table 6. (continued).

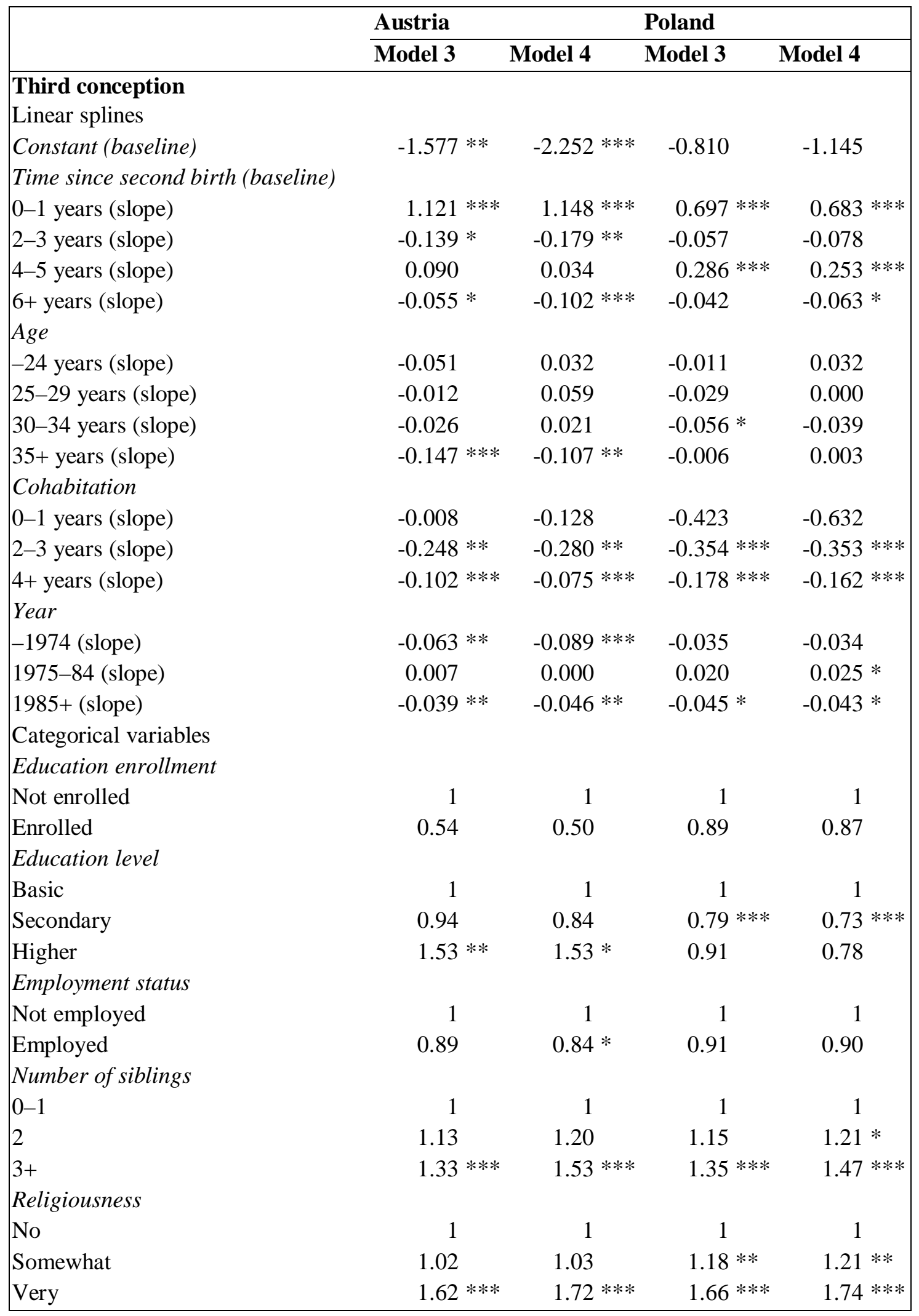

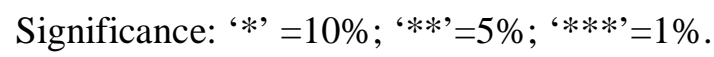

n. e. - not estimated (because of few exposures and occurrences outside of marriage). 


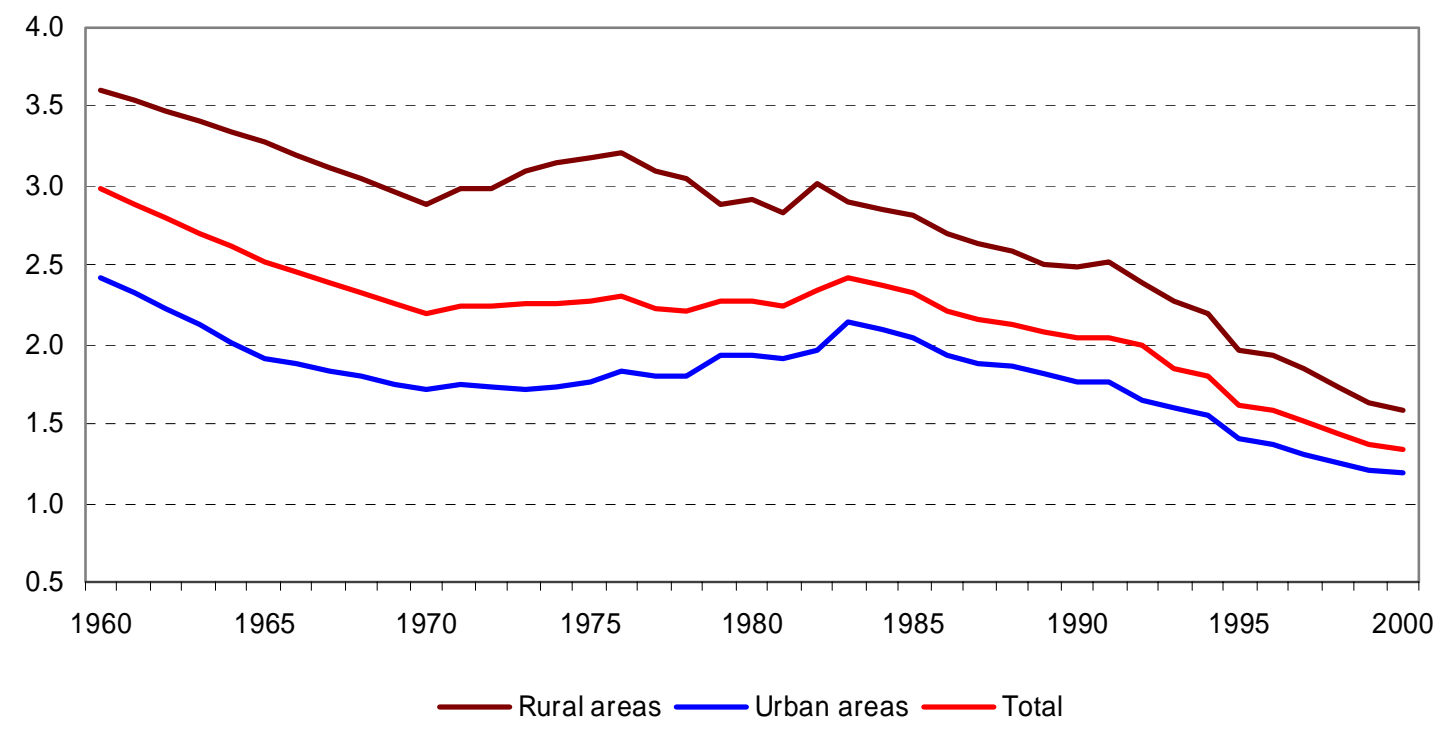

Figure 1. Total fertility rate by type of settlement in Poland. 
Austria

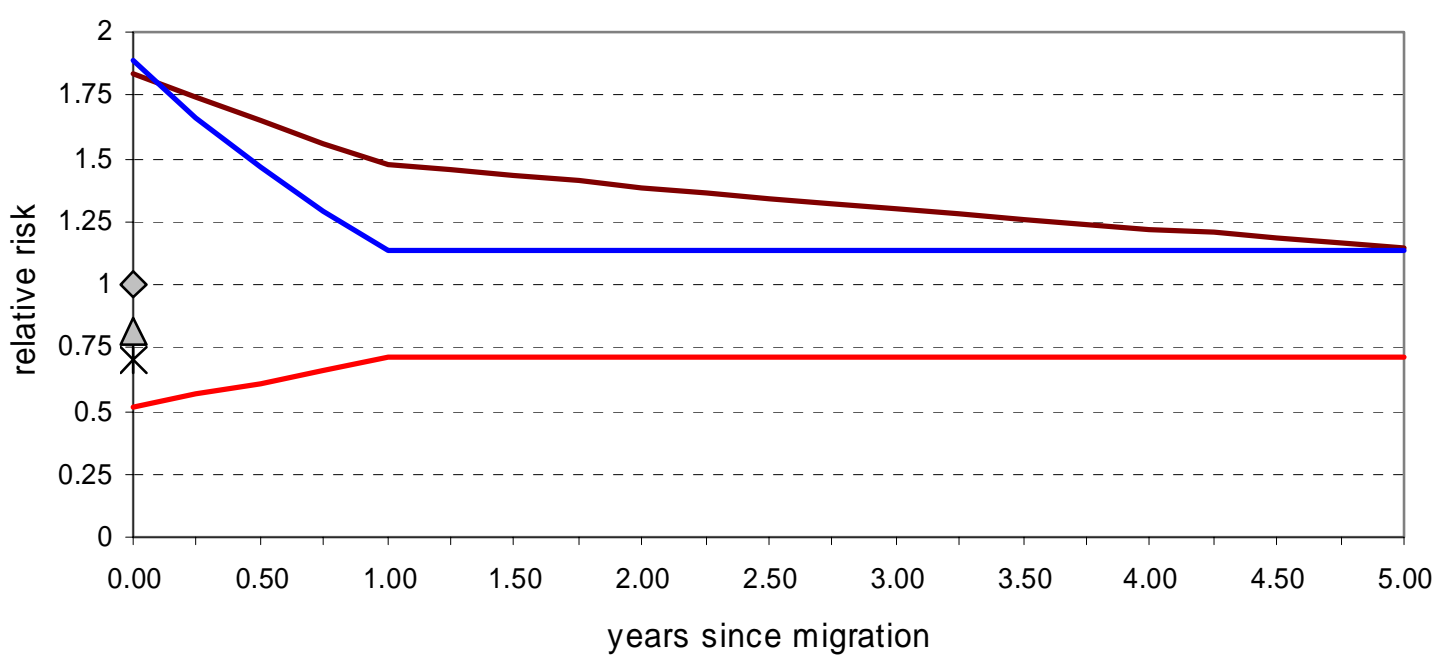

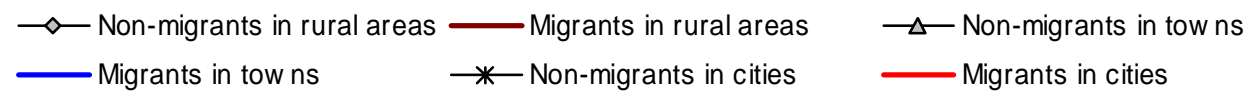

Poland

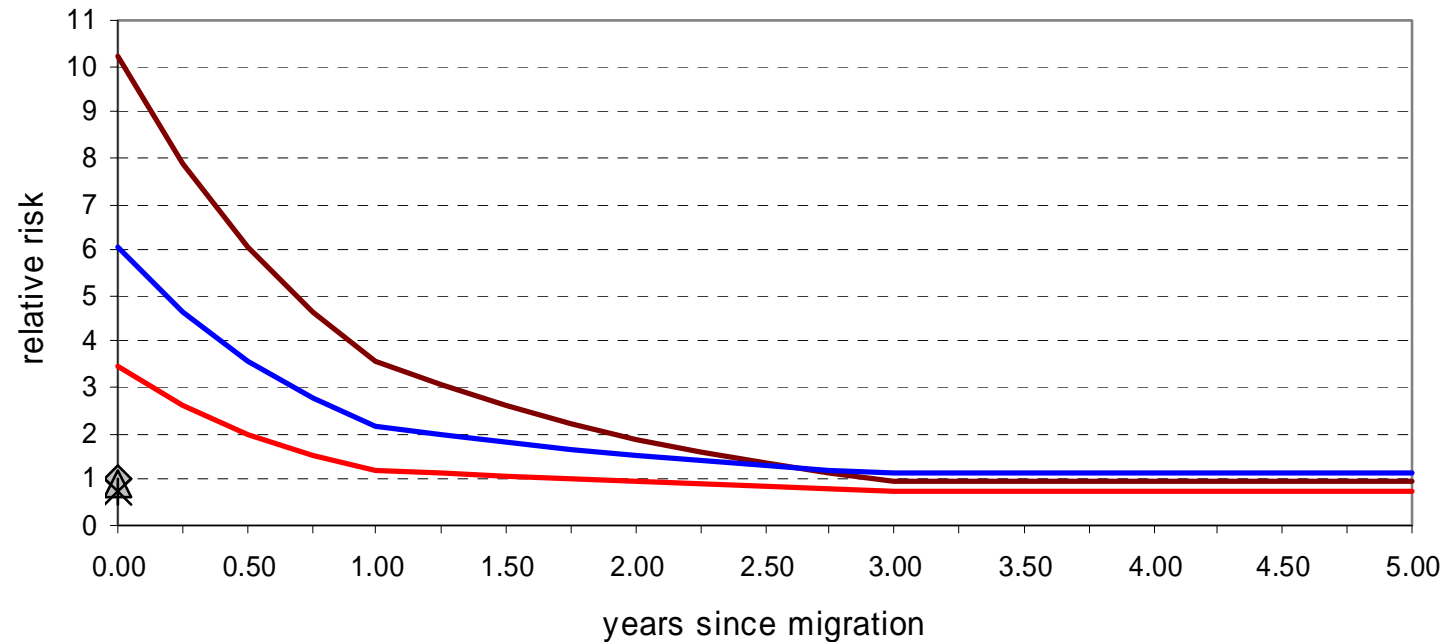

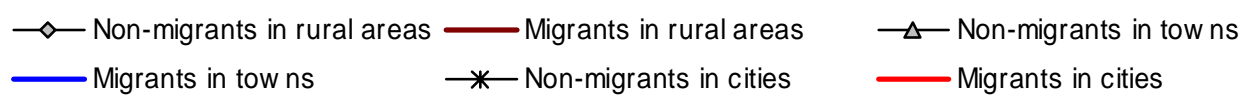

Figure 2. Effect of migration on conception leading to first birth (extended Model 1). 


\section{Austria}

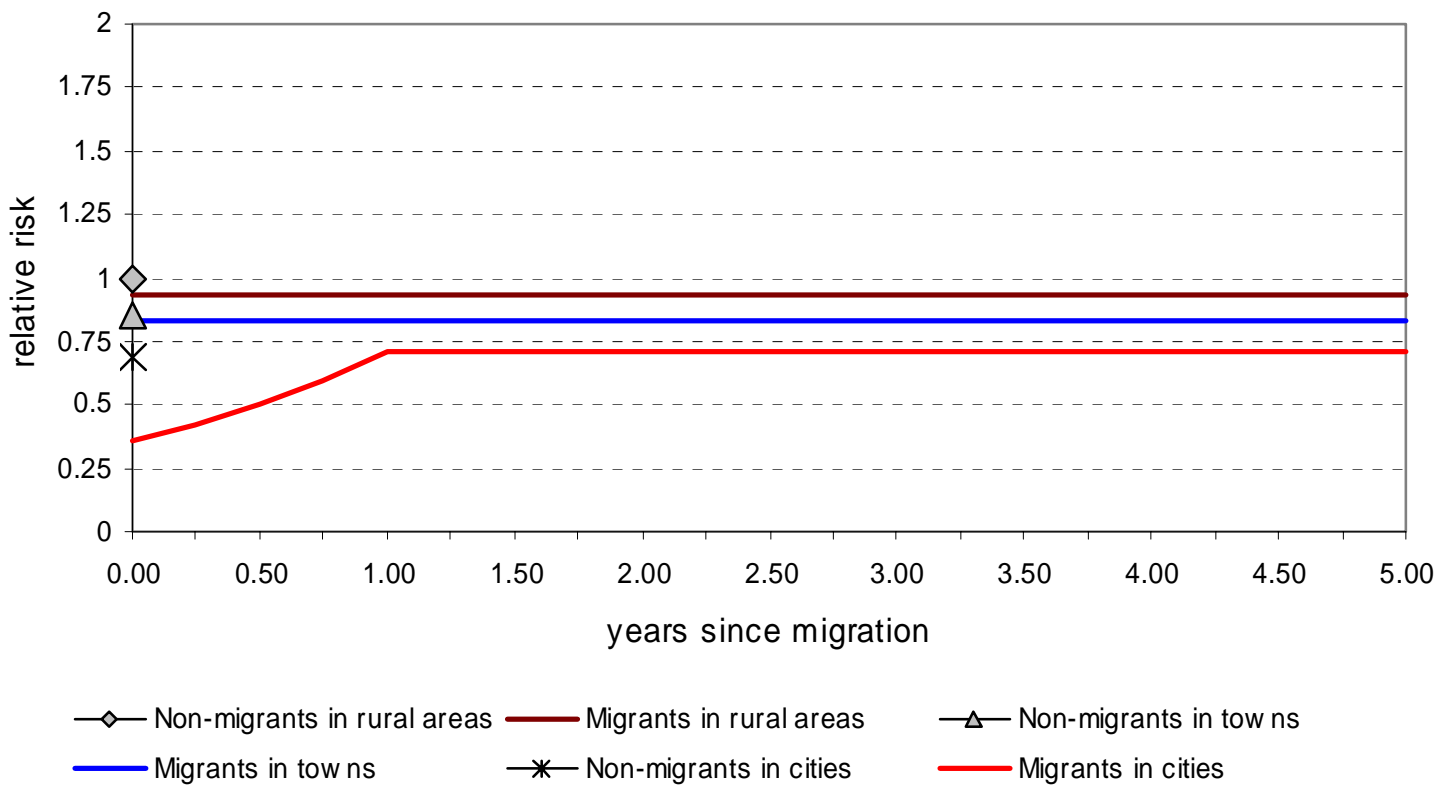

\section{Poland}

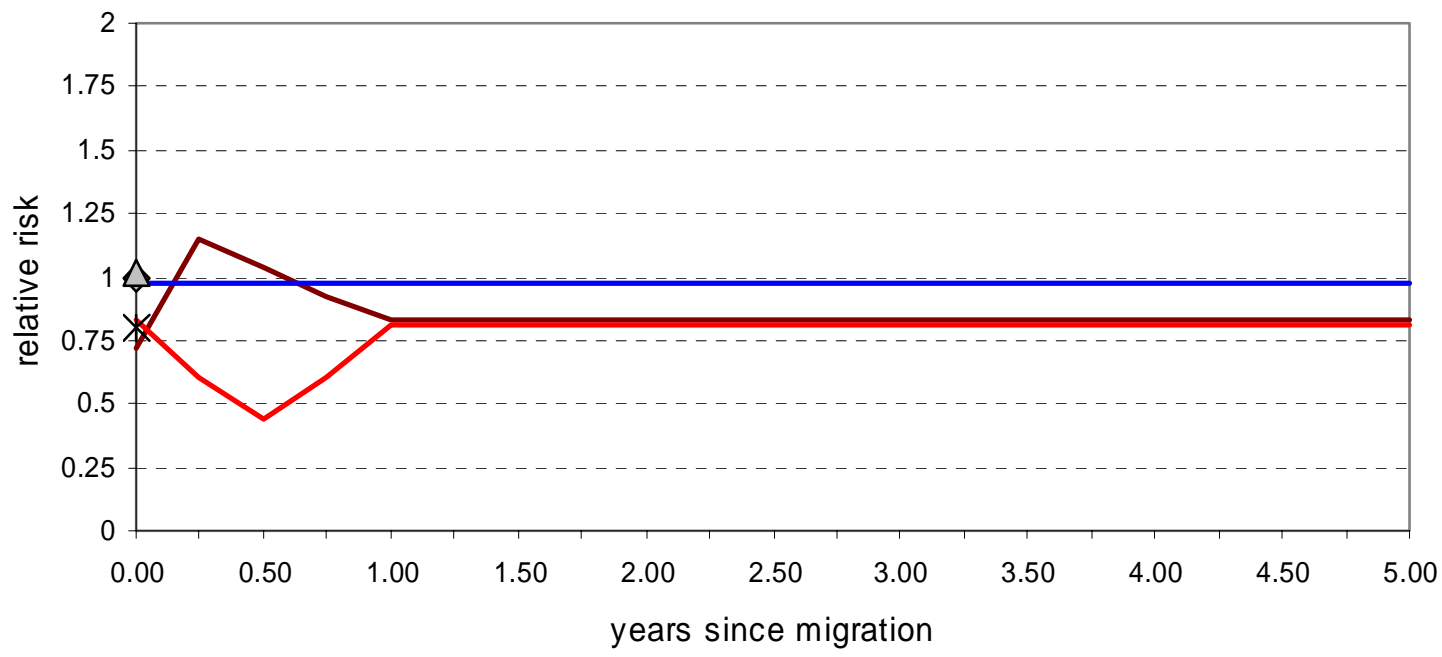

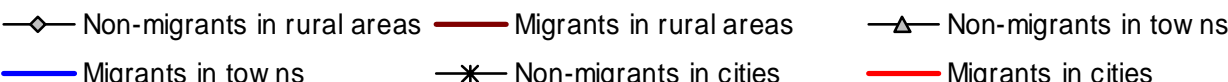

Figure 3. Effect of migration on conception leading to first birth (extended Model 3). 